От вещей - к концептам:

когнитивно-семиотические заметки

о «Доме философа» Чеслава Милоша

\title{
Е. Е. Бразговская
}

ПЕРМСКИЙ ГОСУДАРСТВЕННЫЙ

ГУМАНИТАРНО-ПЕДАГОГИЧЕСКИЙ УНИВЕРСИТЕТ

Аннотация. На материале польскоязычного текста Чеслава Милоша «Dom filozofa» (1991) показаны возможности говорить о вопросах когнитивистики в форме художественного нарратива. Как мыслит философ, почему язык есть его единственный дом - вот темы, предложенные Ч. Милошем.

Логика вербальной репрезентации мира состоит в удалении слова от вещи и работе с ментальными репрезентациями. Философ движется от создания иконических картинок «всего, что есть» к «вычитанию» индивидуальных характеристик вещей. Восходя по ступенькам абстракции, он наделяет автономностью атрибуты (взбегание как таковое) и, наоборот, создает «вещи в себе» (стебли вне обрезающей их девушки, цвета, формы). Картина мира сводится к каталогам, где каждый член (блеск, вскрик «O!») есть знак нечеткого размытого множества. Парадигмы, альтернативная категоризация - это различные способы сжатия информации, которыми пользуется мыслитель. В итоге это путь к рождению концептов.

Бразговская E. E. От вещей - к концептам: когнитивно-семиотические заметки о «Доме философа» Чеслава Милоша // Критика и семиотика. 2019. № 1. С. 339-349.

ISSN 2307-1737. Критика и семиотика. 2019. № 1

(C) Е. Е. Бразговская, 2019 
У философа язык мышления основан на работе с «живыми понятиями». Оборотной стороной слова выступает образ иной модальности, прежде всего визуальной. В «когнитивном танго» языков философа вербальные системы (польский, латинский языки) представлены актуально, тогда как визуальный образ имеет ментальную природу. Глаз философа подобен борхесовскому Алефу, воспринимающему пространство в виде картыобозрения. Его языковое сознание сродни машине времени. По Милошу, свобода перемещения по локусам и временам ставит знак равенства между сознанием человека и Богом, лишенным смертного тела.

Современная наука рассматривает литературу и искусство как периферию когнитивно-семиотических исследований, где образная форма представления знания (а в случае Милоша - его интуитивного предвидения) становится инструментом популяризации данных о работе человеческого мышления. В когнитивистике механизм мышления, о котором говорит Чеслав Милош, описывается в рамках теории ментальных пространств, концептуальной интеграции, двойного кодирования информации, образных схем.

Ключевые слова: ментальная репрезентация, иконические знаки, мультимодальное кодирование, дополнительность языков, концептуализация, Чеслав Милош.

УДК $165.6+81-114.2$

DOI 10.25205/2307-1737-2019-1-339-349

Контактная информация: Бразговская Елена Евгеньевна, доктор филологических наук, профессор, профессор кафедры общего языкознания Пермского государственного гуманитарно-педагогического университета (ул. Сибирская, 24, Пермь, 614990, Россия, elena.brazgowska@gmail.com)

Я хочу, чтобы вы увидели путь к истине не со стороны, а изнутри, двигаясь рядом с проводником.

Александр Мигдал

Понятийный и методологический ландшафты этих заметок определяются прикладным аспектом когнитивно-семиотических исследований дискурсом когнитивной поэтики [Stockwell, 2002]. Однако речь пойдет не столько о когнитивном анализе литературного текста, сколько о художественных опытах мышления о мышлении. На протяжении всей статьи эти опыты будут сопоставляться с результатами собственно научных работ (см. [Paivio, 1986; Fauconnier, Turner, 2002; Johnson, 2005] и др.).

Я обращаюсь к тексту Чеслава Милоша «Dom filozofa» («Дом философа») [Miłosz, 2011]. Визуально и стилистически этот трехстраничный текст 
больше похож на эссе, однако Милош рассматривает его как стихотворный, включая в сборник «Dalsze okolice» (1991) и далее в том «Wiersze wszystkie» (2011). «Дом философа» - редкая в литературе метатекстовая форма, в структуру которой входит авторский комментарий к «основному» тексту (Dom filozofa и komentarz do Domu filozofa). Подобным образом у Милоша организовано и стихотворение «Niebo».

Тему этого текста можно сформулировать в виде серии вопросов. Как мыслит философ? Руководствуется ли он исключительно логикой, создавая свою картину мира, или восхождение от вещей к концептам предполагает также озарение, инсайт, художественное творчество? Читатель получает возможность заглянуть в кабинет безымянного философа, но не затем, чтобы увидеть его книги или его самого, а чтобы со стороны «наблюдать» работу его сознания. «Дом философа» можно определить как когнитивный автопортрет Милоша: сначала показаны этапы мышления, которые философ проходит на пути к целостной (поскольку его жизнь приближается к закату) картине мира. Потом следует аналитический комментарий автора (мышление о мышлении), из которого становится ясно, что философ - это «я» самого поэта. В прямом смысле поэтику этого текста можно определить как когнитивную.

Жанр научных заметок позволяет мне не выносить теоретические предпосылки работы в отдельную часть. Фрагменты авторского текста в статье выделены курсивом. Если они интерпретируются, то приводятся без перевода.

Сеть «живых понятий» и мультимодальный образ мира. Милош пишет о философе, вступившем в период «чистого» мышления. Кровь теперь циркулирует медленнее, всё реже он испытывает мгновения страстных порывов или гнева, всё меньше сожалеет о неизбежном конце своего существования. Утратив иллюзии о возможности непосредственного познания мира, философ отправляется в путешествие среди вещей, которые конструирует его сознание (rzeczy, które ukazuja się za pośrednictwem zmystów). В терминологии когнитивистики, он работает с ментальными репрезентациями и образными схемами, уже не испытывая желания соприкасаться с объектами физического мира.

Философ видит внутренним зрением, как фильм, систему ментальных объектов - жизненных ситуаций, извлекаемых из памяти вне какой-либо логики. Среди них, взбегание женщины в зеленом платье по ступенькам, захлопьвание двери автомобиля, сверкание автострады в мегаполисе. Все эти действия отделены от пространственно-временных контекстов и потому рассматриваются как процессуальные объекты, заключенные в грамматические формы глагольных имен: wzbiegnięcie, trzaśnięcie. Онтологическая сложность этих объектов объясняется тем, что, например, крик «О!» неотделим от боли, которую палец ощущает в момент укола иглой. 
А далее философ начинает восхождение по ступенькам абстракции. Его сознание свободно отделяет атрибуты от очевидностей, форм и вещей. И взбегание обретает онтологическую автономность, поскольку уже не связано ни с «вот этой» женщиной в зеленом пальто, ни с «вот этой» лестницей и даже со ступеньками как таковыми. А вот обратный процесс, в котором происходит рождение «вещей в себе» - предметов, взятых вне своих качеств. Обрезанные стебли цветов, из которых девушка составляет букет, видятся отдельно от букета и девушки. То же и с ногами бездомного на перроне метро: в памяти философа они превращаются в ноги как таковые, словно получившие автономию от тела. Стебли и ноги, взятые как таковые, также пополняют класс абстракций. На последней ступени отвлечения от физических и временны́х локусов философ мысленно перемещает абстракции в контексты различных дискурсивных обстоятельств, которые создаются с помощью логических операторов потому, что (dlatego że), если бы не ( $g d y b y$ niе), если бы ( $g d y b y)$. И, наконец, они интерпретируются в рамках еще более пространных дискурсов - различных теорий и верований.

Логика вербальной репрезентации мира, которой пользуется философ, состоит в удалении слова от вещи. В итоге мир как изначально «переливающаяся через край множественность вещей» (wylewajaca się z brzegów mnogość) сводится к каталогам, редуцируется до карты линейных перечней, где каждый член (взбегание, блеск, вскрик «О!») становится концептуальным знаком нечеткого размытого множества. Всю эту карту философ видит ментальным зрением сверху. Его глаз подобен борхесовскому Алефу, поскольку вбирает в себя одновременность присутствия вещей в любой точке пространства (świadek obecny w każdym momencie czasoprzestrzeni) ${ }^{1}$. В когнитивистике такой способ картирования пространства определяется как карта-обозрение в противоположность карте, по которой можно продвигаться линейно.

Следует ли из этого способа познания, что философ перестает мыслить, как человек, что исчезает антропоморфный принцип описания мира? У американского поэта и коллеги Чеслава Милоша по университету в Беркли Р. Хасса читаем, что, отделяясь от вещи, слово становится элегией для своего означаемого:

A word emphasizes our separation from the particulars $\langle\ldots\rangle$

a word is elegy to what it signifies $<\ldots>$

(«Meditation at Lagunitas») [Hass, 1979, p. 5].

\footnotetext{
${ }^{1}$ Тот же образ встречается и в русской поэзии: О. Мандельштам говорит о «языке пространства, сжатого до точки» [1990, с. 209], И. Бродский - о возможности обретения точки, с которой «я на себя взираю свыше» [2010, с. 170].
} 
Однако у И. Бродского наоборот: «чем бестелесней, тем, видно, одушевленней» («Цветы») [2010, с. 543]. Так насколько далеки от человека абстракции философа?

Милош отмечает: его мыслитель рассматривает свои ментальные объекты как действительно существующие и обладающие относительной эмпирической доступностью. Причина в том, что любое понятие имеет мультимодальную природу, т. е. кодируется не только вербальным знаком. Вербальный язык - не единственный инструмент репрезентации. Философ создает так называемые «живые» понятия, основанные на эффекте синестезии [Зинченко, 2010, с. 269]. Здесь оборотной стороной слова выступает обязательный образ иной модальности (визуальный, тактильный, обонятельный, слуховой), закодированный в вербальном знаконосителе. Например, слово взбегание возникает у философа вместе с ментальной картинкой, где женщина в зеленом пальто быстро поднимается по лестнице. Попытки «очистить» взбегание от субъекта, совершающего это действие, завершаются только заменой одного субъекта на другое действующее лицо. В «когнитивном танго» языков, реализующих семиотический принцип дополнительности систем [Zbikowski, 2006], вербальные системы (у философа это польский и латинский языки) представлены актуально, тогда как визуальный образ имеет ментальную природу.

Описывая мышление философа, Милош делает акцент на вербальновизуальной репрезентации мира. У Милоша, как и у Бродского, восприятие мира начинается с «включения сетчатки», когда «глаз предшествует перу» и «остальные чувства играют еле слышную вторую скрипку» [Бродский, 2006, с. 100, 116]. Милошевский философ обладает окуляцентричным мышлением. Его визуальные образы - своего рода зеркало, в котором вербализованное понятие получает практически эмпирическую доступность. Однако его страсть к визуализациям абстракций (chciwość obrazów) не имеет ничего общего с субъективными представлениями. Образы, которые философ перебирает во время своих ментальных путешествий, - это объективные репрезентации, сопоставимые, как пишет Милош, с теми, что производит объектив фотоаппарата или кинокамеры. Именно «очищенность» ментальных картин от эмоций и субъективности (а это результат категоризации) рождает мысль об объективности отображения.

Языковое сознание философа подобно машине времени, поскольку позволяет ему раздвигать настоящее в прошлое и будущее. Так, философ наблюдает Венецианский Совет Десяти (1310), становится свидетелем создания клинописи - самого древнего вида письма, видит землю, которая существует еще без человека, но уже с пастбищами динозавров, спускается в морские глубины, ощущает холод межпланетного пространства. А при этом его тело существует в минуте сейчас, в XX веке. Из осознания этой антиномии у мыслителя рождается идея Бога, который лишен смертного тела и потому не ограничен в перемещениях по пространственным локу- 
сам и эпохам. У Милоша есть еще один довод в пользу существования Бога. Театр земных образов не может существовать сам по себе ни для кого: у мира должен быть Зритель, Наблюдатель - некий «абсолютный свидетель», включенный в мир и одновременно стоящий над ним. На эту роль претендуют не только Бог, но и сам философ, стремящийся освободить сознание от власти тела. В свою очередь, способность воспринимать серии физических форм доказывает, то мир определенно существует. Милош завершает «основной» текст чеканной латинской максимой: esse est percipi, существовать как быть воспринимаемым.

Еще раз повторю, что в отношении «техники» репрезентации мира Милош ставит в один ряд мыслителя и Бога. В равной степени для обоих характерна страсть к коллекционированию «подробностей» мира в виде иконических знаков и одновременно движение от серии «фотографических» оттисков (того, что есть «на самом деле») - к «вычитанию» индивидуальных характеристик изображенного и далее к категоризации атрибутов, «очищенных» от вещей, а также самих «вещей в себе». В итоге это путь к рождению концептов.

Прочтение «Дома философа» в рамках когнитивной парадигмы не «навязывается» тексту Милоша, а возникает исходя из того, о чём пишет философ или явно отождествляющий себя с ним поэт. Вот какие вопросы затрагиваются в этом тексте, если их перевести из художественного дискурса в пространство когнитивно-семиотических исследований:

- язык, сознание есть дом философа и человека вообще (и это смысл заглавия текста);

- процесс познания мира парадоксален, поскольку ментальные репрезентации всё дальше и дальше удаляют нас от него;

- парадигмы, типизация, альтернативная категоризация - это различные способы сжатия информации, которыми пользуется мыслитель;

- язык мышления основан на работе с «живыми понятиями», которые приближают абстракции к человеку. Синестезия как дополнительность вербального и невербального языков - это матрица культуры.

В когнитивистике механизм мышления, о котором пишет Чеслав Милош, описывается в понятийных рамках теории ментальных пространств, концептуальной интеграции, двойного кодирования информации, образных схем [Paivio, 1986; Johnson, 2005; Fauconnier, 2002; Черниговская, 2013]. Так, любому высказыванию предшествуют ментальные репрезентации, которые выполняют функцию мостика между чувственным восприятием мира и его «форматированием» в виде текста / текстового фрагмента. Прежде всего, речь идет об аналоговой (миметической) репрезентации пространственных перемещений объектов мира: нечто совершает действия, подобные движениям человеческого тела. Отсюда, нет фундаментальной онтологической пропасти между мышлением и телом. Телесность, 
от которой милошевский философ «избавляется» ввиду своей немощности, тем не менее проявляется в метафорическом потенциале его репрезентаций, основанных на сенсорно-моторном опыте. (Об этом же см. в [Gibbs, Colston, 1995, p. 349; Evans, Green, 2006, p. 158].) Эта идея в качестве внутренней формы вписана в английскую лексему embodied (meaning is embodied): значение явлено в теле знака и, в равной степени, включает в себя след представлений о телесности. Вот почему и Милош повторяет: esse est percipi, существовать как быть воспринимаемым.

Почему интересны художественные опыты изучения мышления и сознания? Эти «объекты» не вмещаются в рамки формализованных моделей: говоря о них, мы из области строгой терминосистемы переходим в систему понятий-метафор (например, сознание как сеть). Мультимодальный образ - основа воображения и креативного мышления, которое, по словам А. Эйнштейна, важнее, нежели некое «абсолютное» знание. Вот почему для современной науки литература и искусство - это периферийное пространство когнитивно-семиотических исследований. Как и в науке, здесь ставятся вопросы о функционировании языкового сознания. Но ставятся иначе: в образах и нарративных построениях. При этом кодирование знаний о мире в художественной форме может быть гораздо «полнее и экономичнее, чем в научной» [Черниговская, 2013, с. 26].

Научному открытию может предшествовать озарение, образ. В лекции известного нейробиолога К. В. Анохина «Мозг учёного: как он познаёт истину», прочитанной в декабре 2016 г. на Фестивале науки в МГУ [Анохин, 2016], отмечается, что путь познания определяют не только (а иногда и не столько) логика, но также интуиция ученого и воображение. Но ведь и поэт часто интуитивно предвидит, предчувствует то, что станет предметом научного анализа. Так, американский журналист и популяризатор науки Джона Лерер говорит о том, что Гертруду Стайн можно считать предшественницей Ноама Хомского в разработке идеи глубинной структуры языка, а Марселя Пруста рассматривать как человека, впервые показавшего работу ассоциативных механизмов памяти - пластичность и неопределенность сознания. Они открывали правду о человеческом мышлении, которую ученые затем переоткрывали [Lehrer, 2007, p. 12]. Думаю, Милош тоже входит в указанный круг, и мне не кажется парадоксальным, что некоторые ответы на вопрос о том, как наш мозг (языковое сознание) создает научные или философские репрезентации мира, можно получить, обращаясь и к творчеству поэта.

Мне хочется закончить эту статью упоминанием двух текстов, посвященных человеческому любопытству - первичному источнику создания новых репрезентаций мира как в искусстве, так и в науке. Это книга Альберто Мангеля «Curiositas. Любопытство» [2017] и эссе Чеслава Милоша с тем же названием - «Ciekawość» («Любопытство») [Miłosz, 2010], где он 
уже не скрывается за маской философа. Далее идет свободная цитация обоих источников в силу необычайного совпадения написанного.

Мир устроен столь любопытно, что открытие новых деталей и фактов будет продолжаться бесконечно. Мир - многоуровневый лабиринт, борхесовская Библиотека, и жизнь - неостановимое путешествие: открытие магистралей, маргинальных тропок и тупиков этого лабиринта. Любопытство, страсть, которые заставляют нас узнавать, т. е. жить, - вполне достаточные аргументы против смерти. Это Чеслав Милош.

А вот Альберто Мангель. Знак вопроса нависает над гордячкой-догмой. Вопросы нас возвышают, помогают расти, взлетать, преодолевая гравитацию готового знания. Вопрос переходит в диалог с миром и не требует финальной точки. Вопросительная модальность - двигатель культуры, истории, нашей личности. Интерпретация - не столько утверждения о мире, сколько вопросы, побуждающие к следующей интерпретации.

\section{Список литературы}

Анохин К. В. Мозг учёного: как он познаёт истину. Лекция на Фестивале науки МГУ. 2016. URL: https://www.youtube.com/watch?v=npmuw $\mathrm{IgO} 2 \mathrm{Og}$ (дата обращения 15.02.2018).

Бродский И. Набережная неисцелимых. Эссе / Пер. с англ. Г. Дашевского. СПб.: Азбука-Классика, 2006. 192 с.

Бродский И. Малое собрание сочинений. СПб.: Азбука-классика, 2010. $880 \mathrm{c}$.

Зинченко В. П. Сознание и творческий акт. М.: Языки славянских культур, 2010. 592 c.

Мангель A. Curiositas. Любопытство / Пер. с англ. А. Захаревич. СПб.: Изд-во Ивана Лимбаха, 2017. 472 с.

Мандельштам O. Стихотворения, переводы, очерки, статьи. Тбилиси: Мерани, 1990. $415 \mathrm{c}$.

Черниговская T. В. Чеширская улыбка кота Шрёдингера: язык и сознание. М.: Языки славянской культуры, 2013. 448 с.

Evans V., Green M. Cognitive Linguistics: An Introduction. Edinburgh: Edinburgh University Press, 2006. 830 p.

Fauconnier G., Turner M. The way we think: conceptual blending and the mind's hidden complexities. New York: Basic Books, 2002. 440 p.

Gibbs R. W., Colston H. The cognitive psychological reality of image schemas and their transformations // Cognitive Linguistics. 1995. № 6. P. 347-378.

Hass R. Praise. New York: Harper Collins Publishers, 1979. P. 4-6.

Johnson M. The philosophical significance of image schemas // From perception to meaning: image schemas in cognitive linguistics / Eds. Beate Hampe, Joseph E. Grady. Berlin: Mouton de Gruyter, 2005. P. 15-35. 
Lehrer J. Proust Was a Neuroscientist. Boston; New York: Houghton Mifflin Company, 2007. 307 p.

Miłosz Cz. Ciekawość // Miłosz Cz. Abecadło. Kraków: Wydawnictwo literackie, 2010. S. 97-99.

Miłosz $C z$. Dom filozofa // Miłosz Cz. Wiersze wszystkie. Kraków: Znak, 2011. S. 1039-1041.

Paivio A. Mental Representations: A Dual Coding Approach. Oxford: Oxford University Press, 1986. 322 p.

Stockwell P. Cognitive Poetics. An Introduction. London; New York: Routledge, 2002. 204 p.

Zbikowski L. M. The Cognitive Tango // The Artful Mind: Cognitive Science and the Riddle of Human Creativity / Ed. by Mark Turner. Oxford University Press, 2006. P. 132-150.

\section{Article metadata}

Title: From Things to Concepts: Cognitive-Semiotic Notes about the «House of the Philosopher» by Czesław Miłosz

Author: E. E. Brazgovskaya

Author's e-mail: elena.brazgowska@gmail.com

Author affiliation: Perm State Humanitarian Pedagogical University

Abstract. The article offers a cognitive-semiotic analysis of Czesław Miłosz Polish-language text «Dom filozofa» («A Philosopher's Home», 1991). Simultaneously, we discuss the possibility of talking about the algorithms of thinking in the form of an artistic narrative. How does the philosopher think? This is the theme proposed by Miłosz. The subject of his essay is the steps of abstraction, according to which the philosopher goes to the whole picture of the world.

Philosopher works with mental representations - a system of objects of a complex ontological nature: the woman's running in a green dress on the stairs, slamming the car door. The logic of the verbal representation of the world consists in removing the word from the thing. The philosopher collects the details of the world in the form of iconic signs. Ascending the steps of abstraction, he gives autonomy to attributes (running up as such) and, on the contrary, creates «things in themselves» - objects outside their qualities (stems outside the girl cutting them, color, forms). The multiplicity of the world is reduced to catalogs, where each member ( a scream «Oh!») is a sign of a fuzzy set. The thinker uses the various ways of information compression: paradigms, processes of alternative categorization. In the end, this is the way to the birth of concepts.

The language of thinking is based on working with «living concepts» that bring abstraction closer to a person. The other side of the word is the image of another modality. Miłosz puts the emphasis on the verbal-visual representation of the world - its ocular-centric nature. In the «cognitive tango» of languages, 
two verbal systems (Polish, Latin) are presented in the current mode, while the visual image is of a mental nature.

The philosopher's eye is similar to J. L. Borges's Aleph, allowing to see a space in the form of a «map» - simultaneous plurality of things. His linguistic consciousness is like a time machine. Existing in the twentieth century, the philosopher «watches» the Venice Council of Ten (1310), the birth of cuneiform, dinosaur pastures, intergalactic spaces. According to Miłosz, the freedom of movement through loci and times puts an equal sign between the consciousness of $\mathrm{f}$ man and God, devoid of the mortal body. Modern science is considering the literature and art as a periphery of cognitive-semiotic studies, where the figurative forms of representation of knowledge (and in the case of Miłosz, its intuitive foresight) become a tool for popularizing information about the work of human thinking. In cognitive science the mechanism of thinking, described by Czesław Miłosz, is analyzed in the framework of the theory of mental spaces, conceptual integration, double coding of information, image schemes.

Key terms: mental representation, iconic signs, multimodal coding, complementarity of languages, conceptualization, Czeslaw Milosz.

Reference literature (in transliteration):

Anokhin K. V. Mozg uchenogo: kak on poznaet istinu. Lektsiya na Festivale nauki MGU. 2016. URL: https://www.youtube.com/watch?v=npmuw IgO2Og (accessed: 15.02.2018). (in Russ.)

Brodskiy I. Maloe sobranie sochineniy. St. Petersburg, Azbuka-Klassika Publ., 2010, 880 p. (in Russ.)

Brodskiy I. Naberezhnaya neistselimykh. Esse. Transl. from Engl. by G. Dashevskiy. St. Petersburg, Azbuka-Klassika Publ., 2006, 192 p. (in Russ.)

Chernigovsraya T. V. Cheshirskaya ulybka kota Shryodingera: yazyk i soznanie. Moscow, Yazyki slavyanskoi kultury, 2013, 448 p. (in Russ.)

Evans V., Green M. Cognitive Linguistics: An Introduction. Edinburgh, Edinburgh University Press, 2006, 830 p.

Fauconnier G., Turner M. The way we think: conceptual blending and the mind's hidden complexities. New York, Basic Books, 2002, 440 p.

Gibbs R. W., Colston H. The cognitive psychological reality of image schemas and their transformations. Cognitive Linguistics, 1995, no. 6, p. 347-378.

Hass R. Praise. New York, Harper Collins Publ., 1979, p. 4-6.

Johnson M. The philosophical significance of image schemas. From perception to meaning: image schemas in cognitive linguistics. Eds. Beate Hampe, Joseph E. Grady. Berlin, Mouton de Gruyter, 2005, p. 15-35.

Lehrer J. Proust Was a Neuroscientist. Boston, New York, Houghton Mifflin Company, 2007, $307 \mathrm{p}$.

Mandelshtam O. Stikhotvoreniya, perevody, ocherki, statii. Tbilisi, Merani Publ., 1990, 415 p. (in Russ.)

Mangel A. Curiositas. Lyubopytstvo. Transl. from Engl. by A. Zakharevich. St. Petersburg, Ivan Limbakh Publ., 2017. 472 p. (in Russ.) 
Miłosz Cz. Ciekawość. In: Miłosz Cz. Abecadło. Kraków, Wydawnictwo literackie, 2010, s. 97-99. (in Pol.)

Miłosz Cz. Dom filozofa. In: Miłosz Cz. Wiersze wszystkie. Kraków, Znak, 2011, s. 1039-1041. (in Pol.)

Paivio A. Mental Representations: A Dual Coding Approach. Oxford, Oxford University Press, 1986, 322 p.

Stockwell P. Cognitive Poetics. An Introduction. London, New York, Routledge, 2002, 204 p.

Zbikowski L. M. The Cognitive Tango. The Artful Mind: Cognitive Science and the Riddle of Human Creativity. Ed. by Mark Turner. Oxford University Press, 2006, p. 132-150.

Zinchenko V. P. Soznanie i tvorcheskiy akt. Moscow, Yazyki slavyanskikh kultur, 2010, 592 p. (in Russ.)

DOI 10.25205/2307-1737-2019-1-339-349 